\title{
The Association of Human Cytomegalovirus with Biomarkers of Inflammation and Immune Activation in HIV-1-Infected Women
}

\author{
Nell S. Lurain, Barbara A. Hanson, Anna L. Hotton, ${ }^{2}$ Kathleen M. Weber, \\ Mardge H. Cohen, ${ }^{2}$ and Alan L. Landay ${ }^{1}$
}

\begin{abstract}
Three groups of cytomegalovirus (CMV)-seropositive women (total $n=164$ ) were selected from the Chicago Women's Interagency HIV-1 Study to investigate the association between CMV coinfection and immune activation: (1) HIV-1 viremic, (2) HIV-1 aviremic, and (3) HIV-1 uninfected. Quantitative measures of CMV serum IgG, CMV DNA, and serum biomarkers interleukin (IL)-6, soluble CD163 (sCD163), soluble CD14 (sCD14), and interferon gamma-induced protein (IP10) were obtained. Levels of CMV IgG and the serum biomarkers were significantly higher in the HIV-1 viremic group compared to the aviremic and uninfected groups $(p<0.001)$. No significant associations with CMV IgG levels were found for HIV-uninfected women. When each of the HIVinfected groups was analyzed, sCD14 levels in the viremic women were significantly associated with CMV IgG levels with $p<0.02$ when adjusted for age, CD4 count, and HIV viral load. There was also a modest association ( $p=0.036$ ) with IL-6 from plasma and cervical vaginal lavage specimens both unadjusted and adjusted for CD4 count and HIV viral load. The association of CMV IgG level with sCD14 implicates the monocyte as a potential site for interaction of the two viruses, which eventually may lead to non-AIDS-defining pathological conditions.
\end{abstract}

\section{Introduction}

$\mathbf{H}$ UMAN CYTOMEgALOVIRUS (CMV), a member of the herpesvirus family, produces infections in immunocompetent persons that are usually asymptomatic. It is mainly in the context of immunosuppression such as HIV/AIDS that CMV infection results in serious sight-threatening or life-threatening disease. ${ }^{1,2}$ In the era before combination antiretroviral therapy (cART) became available, CMV coinfection produced significant end-organ disease as HIV-1infected patients progressed to $\mathrm{AIDS}^{3}$ With the introduction of cART the incidence of symptomatic CMV disease in these patients has been greatly reduced, and non-AIDS-defining conditions have become the major cause of morbidity and mortality associated with HIV-1 infection. ${ }^{4,5}$

CMV like HIV-1 establishes lifelong latency, and recent studies have suggested that periodic asymptomatic CMV reactivations in HIV-1-coinfected persons over a lifetime may contribute to non-AIDS-defining morbidity including cardiovascular disease, neurocognitive impairment, cancer, and renal disease. $^{5-11}$ Despite undetectable levels of HIV-1 and CMV in plasma, these patients may continue to have increased levels of biomarkers of inflammation and immune activation such as interleukin (IL)-6, interferon gamma-induced protein (IP10), as well as markers of monocyte activation soluble CD163 (sCD163) and soluble CD14 (sCD14). All of these biomarkers have been associated with a greater risk of cardiovascular disease and all-cause mortality as reported in several studies. $5,12-21$ Thus, it appears that the inflammatory response to CMV reactivation and replication could be linked to endothelial cell damage that in turn could lead to subclinical vascular changes and atherosclerosis. $6,8,22-24$

Although there have been multiple studies of CMV coinfection in HIV-infected patients, the results have not always been consistent, which may be attributed in part to differences in study populations and types of specimens analyzed. The genome copies of CMV DNA in plasma from CMVseropositive patients who are HIV-1 negative or who have undetectable plasma HIV-1 RNA are almost always below the lower limit of assay detection, which makes CMV reactivation as measured by DNA difficult to assess in asymptomatic patients who have $\mathrm{CD} 4^{+} \mathrm{T}$ cell counts above 200 cells $/ \mathrm{mm}^{3}$, even when they have measurable HIV-1 viral loads. Therefore, plasma specimens obtained for routine medical care are not reliable for use in studies of CMV DNA as a quantitative marker of virus reactivation. However, specimens from other

\footnotetext{
${ }^{1}$ Department of Immunology/Microbiology, Rush University Medical Center, Chicago, Illinois.
}

${ }^{2}$ The CORE Center, Cook County Health and Hospital System, Chicago, Illinois. 
compartments such as semen, saliva, or cervicovaginal lavage (CVL) may have detectable CMV DNA when the CMV plasma DNA remains negative. ${ }^{25}$

Several studies in HIV-1-infected men have used semen specimens to establish an association between CMV shedding and both HIV-1 shedding and increased levels of HIV-1 proviral DNA. ${ }^{26-30}$ Others have reported detectable levels of CMV DNA in CVL, saliva, and peripheral blood mononuclear cells (PBMCs). ${ }^{25,31,32}$ However, immunological markers of CMV infection in blood specimens have shown significant associations with biomarkers of inflammation and non-AIDSdefining events. Therefore, quantitative measures of the immune response to CMV have been used to establish associations with biomarkers of inflammation and disease conditions in HIV-1 patients. CMV-specific $\mathrm{T}$ cell counts and quantitative CMV IgG levels have been used most often., CMV-specific $\mathrm{T}$ cell responses were found to be strongly associated with carotid intima-media thickness in HIV-infected patients compared to HIV-uninfected controls. ${ }^{24} \mathrm{CMV}$ specific $\mathrm{CD}^{+} \mathrm{T}$ cell counts have been reported to remain elevated after successful cART, which may lead to immunosenescence and age-related morbidity. ${ }^{8}$ Other studies have reported CMV IgG associated with cardiovascular and cerebrovascular disease in HIV-1- suppressed patients. ${ }^{7,9,21}$ However, others have not found any association between CMV IgG and non-AIDS-defining conditions in cART-suppressed patients. ${ }^{16,33}$ Therefore the pathogenesis of CMV coinfection in cART-treated HIV-infected patients remains unclear.

The goal of this exploratory study was to investigate the impact of the inflammatory effects associated with CMV/ HIV coinfection in a well-characterized cohort of women, because many prior studies have examined the effects of these two viruses in predominantly male cohorts. ${ }^{7,16,21,33,34}$ The study was designed to quantitate and compare levels of CMV IgG with levels of markers of inflammation and immune activation across three groups of women: (1) HIV seronegative, (2) HIV seropositive/viremic, and (3) HIV seropositive/aviremic. We sought to test whether CMV IgG levels were associated with the levels of HIV viremia and the levels of these markers and whether the observed associations remained after adjustment for known sociodemographic and clinical confounders.

\section{Materials and Methods}

\section{Selection of subjects}

All women were enrolled in the Chicago site of the Women's Interagency HIV-1 Study (WIHS), an ongoing multisite prospective cohort study of women with and at risk for HIV-1 infection in the United States. Detailed information on recruitment and data collection has been described previously. ${ }^{35,36}$ Briefly, at semiannual visits, women undergo clinical examination and provide laboratory specimens and self-reported sociodemographic and behavioral information via surveys administered by trained research staff. Written informed consent was obtained from all participants in accordance with Department of Health and Human Services guidelines, after approval by the Institutional Review Board at each participating site.

There were 296 women actively enrolled at the Chicago WIHS site at the time of the study; 217 (73\%) were HIV infected and $79(27 \%)$ were HIV uninfected. Samples were selected from women with available information on HIV-1 viral load at two consecutive WIHS visits for whom sufficient quantity of samples were available from the specimen repository. Women were categorized into three mutually exclusive groups based on HIV status and HIV RNA levels over the 2 years prior to the CMV study. Eligible patients included the 79 women who were HIV negative at the most recent WIHS visit, 108 HIV-infected women with undetectable HIV RNA (<50 copies/ml) at consecutive WIHS visits for at least 1 year, and 67 women with at least one visit with HIV RNA levels of $\geq 1,000$ copies/ml. Samples were then randomly selected from within these three groups to ensure approximately equal numbers in each group.

The most recent visit was used for women who had more than one visit at which these criteria were met, and women could be included in only one group. The visit at which CMV was measured corresponded to the visit at which women were viremic, or for aviremic women, the visit at which they had been aviremic for at least 1 year. A total of 175 women who met the criteria were screened for CMV seropositivity (60 HIV negative, $60 \mathrm{HIV}$ aviremic, and $55 \mathrm{HIV}$ viremic with HIV RNA $\geq 1,000$ copies $/ \mathrm{ml}$ ). There were $164 \mathrm{CMV}$ seropositive subjects $(93.7 \%)$ divided approximately evenly among the three groups: $54 \mathrm{HIV}$ uninfected, $58 \mathrm{HIV}-1$ aviremic, and $52 \mathrm{HIV}-1$ viremic. CMV-seronegative women were excluded, because there were only 11 women identified in this category. CMV and immune activation markers were measured from specimens collected at the time of the corresponding study visit for all women.

Serum, plasma, and CVL specimens from all the CMVseropositive women were tested. Sociodemographics included age in years, race/ethnicity, annual household income (categorized as $<\$ 18,000$ vs. $\geq \$ 18,000$ ), educational attainment (less than high school vs. high school or equivalent or higher education), and current employment. Clinical variables included HIV-1 RNA and CD4 count, hepatitis $\mathrm{C}$ virus (HCV) coinfection (based on antibody positivity measured at WIHS enrollment), clinically significant depressive symptoms using a cutoff of 16 measured by the Centers for Epidemiologic Studies-Depression (CESD), ${ }^{37}$ current smoking status, diabetes (by self-report or any use of antidiabetic medication, fasting glucose $\geq 126$, or hemoglobin $A_{1 c} \geq 6.5 \%$ ), hypertension (based on self-report, systolic blood pressure $\geq 140$, diastolic blood pressure $\geq 90$, and/or use of antihypertensive medications), estimated glomerular filtration rate (eGFR) based on the Modification of Diet in Renal Disease (MDRD) Study, $\mathrm{eGFR}=\left[186 \times(\right.$ serum creatinine -1.154$) \times(\text { age })^{-0.203} \times(0.742$ if female $) \times(1.210$ if African American $)],{ }^{38}$ and current body mass index (BMI; calculated as weight in kilograms/height in meters $^{2}$ ).

\section{Quantitation of CMV IgG}

CMV IgG antibody levels were measured in serum using the Cytomegalovirus IgG Enzyme Immunoassay kit (ELISA, GenWay Biotech, San Diego, CA). Samples were diluted 1:80 for the initial assay and the OD was read at $450 \mathrm{~nm}$, using a DuPont Kinetic Microplate Reader (Molecular Devices, Sunnyvale, CA). All samples below the assay cutoff were repeated at a 1:40 dilution. Quantitative results in international units per milliliter were calculated using kit calibrators. 


\section{Quantitation of CMV DNA}

A validated in-house TaqMan real-time PCR assay was used to measure CMV DNA in plasma and whole CVL. DNA was extracted from specimens using the DNA Mini Kit (QIAGEN, Valencia, CA). The target sequence is the CMV DNA polymerase gene. The primer and probe sequences are forward CTCGTGCGTGTGCTACGAGA; reverse GCCGA TCGTRAAGAGATGAAGAC; probe FAM-AGTGCAGCC CC GRCCATCGTTC-TAMRA. The lower limit of detection of the assay is 100 copies $/ \mathrm{ml}$.

\section{Quantitation of HIV-1 RNA}

HIV-1 plasma RNA was measured using the COBAS AmpliPrep/COBAS TaqMan HIV-1 Test version 2.0 (Roche). The assay had a lower limit of detection of 20 copies $/ \mathrm{ml}$. CVL specimens were centrifuged, and the supernatant fluid was analyzed for HIV-1 RNA using the Abbott RealTime HIV-1 Assay with a lower limit of detection of 40 copies $/ \mathrm{ml}$.

\section{Quantitation of markers of inflammation and immune activation}

Plasma specimens were analyzed for several biomarkers of inflammation and activation by commercially available ELISA kits: IL-6 (R\&D, Minneapolis, MN), IP10 (R\&D), sCD14 (R\&D), and sCD163 (Trilium Diagnostics, Brewer, ME). IL-6 levels were also measured in CVL specimens.

\section{Statistical methods}

Demographic and clinical characteristics, inflammatory markers, and CMV IgG levels were compared among the three groups of women using chi-square tests for categorical variables and Kruskal-Wallis tests for nonnormally distributed continuous variables. Post hoc tests were conducted for variables for which overall group differences were observed to test the statistical significance of differences among subgroups, using the Holm method of adjustment for multiple testing. ${ }^{39}$ Associations of CMV with sociodemographic and clinical variables and inflammatory markers were assessed using Spearman rank correlation coefficients for comparison of two nonnormally distributed continuous variables and Wilcoxon tests or Kruskal-Wallis tests for nonparametric comparison of CMV IgG distribution across two or more categories. Nonparametric tests were used due to significant skewness in the distribution of inflammatory makers and CMV IgG, which was not improved by transformation. Spearman partial correlations were used to assess associations among variables adjusted for potential confounders (age, CD4 count, viral load, and $\mathrm{HCV}$ ).

Confounders were selected for analysis based on previous literature and a priori hypotheses about associations with CMV and/or inflammatory markers and associations observed in exploratory analysis. We do not present multivariable regression results because of the small sample size, exploratory nature of the study, and failure of several of the inflammatory markers to meet distributional assumptions necessary for linear regression. To account for multiple tests of significance in assessing associations of CMV IgG with inflammatory markers within each of the three subgroups, false discovery rate adjusted $p$-values were calculated using the Benjamini and
Hochberg method. ${ }^{40}$ Analyses were conducted using SAS software version 9.3 (SAS Institute, Cary, NC).

\section{Results}

\section{Study demographics}

The median age (51.0 years) of the HIV-1 aviremic group was higher $(p<0.001)$ than the median age of either the HIV1 viremic group (43.5) or the HIV-1-uninfected group (44.5) (Table 1). The racial distribution among the groups was similar with the majority of the women being African American. A significantly higher percentage of the HIV-1uninfected women was currently employed, while the HIV-1 viremic group had the lowest percentage of employment $(p=0.010)$. The HIV-1 viremic group had a lower household income $(p=0.035)$ and less education $(p=0.06)$ than the other two groups. There were no significant differences among the groups for the time of WIHS enrollment (1994/ 1995, 2001/2002, 2011/2012).

\section{Markers of CMV infection}

For this study only the women who were CMV seropositive were included, because only $11 \mathrm{CMV}$-seronegative women were identified in the eligible cohort. Quantitative levels of CMV IgG were significantly higher in the HIV-1 viremic group compared to the other two groups $(p=0.009)$ (Table 1). Only five women (3.0\%) had detectable CMV DNA in plasma, which was not associated with HIV-1 RNA or CMV IgG levels, although the power to detect differences was limited by the small number of women. These data are consistent with previous reports that CMV DNA is infrequently detected in plasma of patients with CD4 counts $>200$ cells $/ \mathrm{mm}^{3}{ }^{32,41}$ Thirty-one women $(18.9 \%)$ had measurable CMV DNA in CVL with a significantly higher proportion among HIV-1 viremic women (Table 1). There was no association between plasma and CVL CMV DNA (Spearman $r=0.005 ; p=0.950)$. Among those with detectable CMV DNA in CVL $(n=31)$ there was no association between CMV DNA in CVL and CMV IgG (Spearman $r=0.02 ; p=0.902$ ). CMV DNA in CVL was also not associated with HIV RNA in plasma (Spearman $r=0.13 ; p=0.575$ ) or HIV RNA in CVL (Spearman $r=0.2 ; p=0.800$ ).

Although CMV DNA was detected more frequently in CVL than in plasma (Table 1), we found that CVL had a much lower level of detection and copy number of CMV DNA compared to results reported for semen. ${ }^{2,30,32}$ This could be an effect of dilution from the lavage technique in which a $10 \mathrm{ml}$ volume of saline is injected to collect the secreted virus.

\section{Clinical characteristics of the study cohort}

There were significant differences in $\mathrm{T}$ cell counts among the three groups (Table 1). Not surprisingly, $\mathrm{CD}^{+} \mathrm{T}$ cell counts were significantly higher in the HIV-1-uninfected group compared to each of the HIV-1-infected groups, and for HIV-1 aviremics the counts were significantly higher than for the HIV-1 viremic women (all $p$ values $<0.001$ ). Conversely, the $\mathrm{CD} 8^{+} \mathrm{T}$ cell counts were significantly higher for the viremic women compared to the HIV-negative women $(p<0.001)$. As predicted, the median $\mathrm{CD} 4^{+} / \mathrm{CD}^{+}$ratio for the HIV-1-uninfected group was the highest (2.13) followed 
Table 1. Patient Characteristics by HiV-1 Status, $N=164$

\begin{tabular}{|c|c|c|c|c|}
\hline & $\begin{array}{l}\text { HIV uninfected } \\
\quad(\mathrm{n}=54)\end{array}$ & $\begin{array}{l}\text { HIV infected aviremic } \\
\qquad(\mathrm{n}=58)\end{array}$ & $\begin{array}{l}\text { HIV infected viremic } \\
\quad(\mathrm{n}=52)\end{array}$ & \\
\hline Characteristic & Median (IQR) or $\mathrm{n}(\%)$ & Median (IQR) or $\mathrm{n}(\%)$ & Median (IQR) or n (\%) & $\mathrm{p}-$ value $^{\mathrm{a}}$ \\
\hline \multicolumn{5}{|l|}{ Sociodemographic variables } \\
\hline Age, years & $44.5(39-52)$ & $51(45-55)$ & $43.5(37-49)$ & $<0.001$ \\
\hline Race/ethnicity & & & & \\
\hline African American/black & $45(83.3)$ & $44(75.9)$ & $46(88.5)$ & 0.229 \\
\hline Hispanic & $7(13.0)$ & $6(10.3)$ & $3(5.8)$ & \\
\hline White/other & $2(3.7)$ & $8(13.8)$ & $3(5.8)$ & \\
\hline Currently employed $^{\dagger}$ & $25(47.2)$ & $20(34.5)$ & $10(19.2)$ & 0.010 \\
\hline $\begin{array}{l}\text { Annual household } \\
\text { income }<\$ 18,000\end{array}$ & $34 / 54(63.0)$ & $35 / 56(62.5)$ & $37 / 44(84.1)$ & 0.035 \\
\hline $\begin{array}{l}\text { Education less than high } \\
\text { school }\end{array}$ & $16(29.6)$ & $15(25.9)$ & $24(46.2)$ & 0.060 \\
\hline \multicolumn{5}{|l|}{ Clinical variables } \\
\hline $\mathrm{CMV}$ IgG, IU/ml ${ }^{*} \dagger$ & $32.9(21.2-39.5)$ & 31.7 (21.4-39.9) & $38.6(32.0-43.1)$ & 0.009 \\
\hline \multicolumn{5}{|l|}{ CMV DNA in CVL } \\
\hline Present, $n(\%)^{*}$ & $11(20.4)$ & $5(8.62)$ & $15(28.9)$ & 0.024 \\
\hline Median (IQR) ${ }^{\mathrm{b}}$ & $658.0(393.0-1365.0)$ & $569.0(355.0-584.0)$ & $1378.0(595.0-2587.0)$ & 0.196 \\
\hline CMV DNA in plasma $(\%)$ & $1(1.9)$ & $3(5.2)$ & $1(1.9)$ & 0.622 \\
\hline $\mathrm{CESD}^{\mathrm{c}} \geq 16$ & $13(24.1)$ & $17(29.3)$ & $22(44.0)$ & 0.080 \\
\hline Current smoker & $29(53.7)$ & $24(41.4)$ & $29(56.9)$ & 0.226 \\
\hline Diabetes ever $^{\mathrm{d}}$ & $8(14.8)$ & $17(29.3)$ & $11(21.2)$ & 0.178 \\
\hline Hypertension (current) ${ }^{\mathrm{e}}$ & $23(42.6)$ & $31(53.5)$ & $24(46.2)$ & 0.501 \\
\hline $\mathrm{BMI}^{\mathrm{f}}$ & $31.0(26.6-36.8)$ & $29.6(25.1-34.0)$ & $25.6(22.8-33.0)$ & 0.037 \\
\hline $\mathrm{eGFR}^{\mathrm{g}}$ & $92.0(78.5-103.1)$ & $86.1(73.9-98.5)$ & $93.9(80.1-114.3)$ & 0.105 \\
\hline $\begin{array}{l}\mathrm{HCV} \text { positive by } \mathrm{Ab} \\
\text { or RNA }\end{array}$ & $6(11.3)$ & $13(22.4)$ & $12(23.5)$ & 0.209 \\
\hline $\begin{array}{l}\mathrm{CD}^{+} \mathrm{T} \text { cell count } \\
\quad\left(\text { cells } / \mathrm{mm}^{3}\right) *,+\dagger\end{array}$ & $1046(843-1224)$ & $763.5(581-958)$ & $321.5(178-515)$ & $<0.001$ \\
\hline $\begin{array}{l}\mathrm{CD}^{+} \mathrm{T} \text { cell count } \\
\left(\text { cells } / \mathrm{mm}^{3}\right)^{\dagger, t}\end{array}$ & $468(357-606)$ & $737.5(529-1003)$ & $781.5(463-1135)$ & $<0.001$ \\
\hline CD4/CD8 ratio $*,+$, & $2.13(1.59-2.77)$ & $1.16(0.77-1.50)$ & $0.36(0.26-0.66)$ & $<0.001$ \\
\hline Raltegravir use (current) & NA & $12(20.7)$ & $5(9.6)$ & 0.109 \\
\hline Any ART use (current)* & NA & $55(94.8)$ & $28(53.9)$ & $<0.001$ \\
\hline Adherence $\geq 95 \%$ h,* & NA & $51 / 55(92.7)$ & $13 / 28(46.4)$ & $<0.001$ \\
\hline $\begin{array}{l}\log _{10} \mathrm{HIV}-1 \text { RNA in } \\
\text { plasma, median (IQR) }\end{array}$ & NA & NA & $4.4(3.7-4.8)$ & NA \\
\hline $\begin{array}{l}\log _{10} \mathrm{HIV}-1 \mathrm{RNA} \text { in CVL } \\
\text { median (IQR) }\end{array}$ & NA & NA & $2.6(2.3-3.1)$ & NA \\
\hline$>40$ copies/ml, $n(\%)$ & NA & $1 / 58(1.72)$ & $21 / 51(41.2)$ & $<0.001$ \\
\hline$<40$ copies/ml, $n(\%)$ & NA & $0 / 58(0.00)$ & 6/51 (11.8) & \\
\hline Negative, $n(\%)$ & NA & $57 / 58(98.3)$ & $24 / 51(47.1)$ & \\
\hline \multicolumn{5}{|l|}{ Inflammatory markers } \\
\hline IL-6 Plasma* & $1.96(1.29-4.28)$ & $1.22(0.79-3.61)$ & $2.34(1.45-6.13)$ & 0.030 \\
\hline IL-6 CVL & $0.91(0.16-4.01)$ & $0.48(0.16-2.22)$ & $1.51(0.25-7.05)$ & 0.063 \\
\hline IP10*,t & $156.51(114.05-205.58)$ & $230.70(190.20-372.00)$ & $527.89(348.80-709.82)$ & $<0.001$ \\
\hline $\operatorname{sCD} 14 *, \dagger, *$ & $5,868.85(5,163.93-6,803.28)$ & $7,339.29(5,428.57-9,280.37)$ & $8,805.19(6,785.71-12,194.81)$ & $<0.001$ \\
\hline $\mathrm{sCD} 163 *, \dagger,+$ & $49.19(36.00-62.74)$ & $63.69(46.25-81.83)$ & $86.05(69.38-111.42)$ & $<0.001$ \\
\hline
\end{tabular}

${ }^{a} p$-values were calculated by Kruskal-Wallis test for continuous variables and chi-square tests for categorical variables (Fisher's exact test for cell sizes $<5$ ), and represent the overall test for differences between the three groups.

${ }^{\mathrm{b}}$ Among those with CMV DNA present in CVL $(n=31)$.

${ }^{\mathrm{c}}$ Centers for Epidemiologic Studies-Depression.

${ }^{\mathrm{d}}$ Ever self-reported antidiabetic medication or any of fasting glucose $\geq 126$ or hemoglobin $\mathrm{A}_{1 \mathrm{c}} \geq 6.5 \%$ or self-reported diabetes is confirmed.

${ }^{\mathrm{e}}$ Any indication of hypertension ( $\mathrm{SBP} \geq 140$, DBP $\geq 90$, self-report, or use of antihypertensive medications) at visit.

f Body mass index.

${ }^{\mathrm{g}}$ Estimated glomerular filtration rate, $\mathrm{ml} / \mathrm{min} / 1.73 \mathrm{~m}^{2}: \mathrm{GFR}=186 \times(\mathrm{Pcr})^{\wedge}(-1.154) \times(\mathrm{age})^{\wedge}(-0.203) \times(0.742$ if female $) \times(1.210$ if black $)$.

${ }^{\mathrm{h}}$ Among those on ART.

${ }^{i}$ Among those with HIV-1 RNA present in CVL $(n=22)$.

$* p<0.05$ for comparison of HIV-infected viremic vs. aviremic.

$p<0.05$ for comparison of HIV-infected viremic vs. HIV uninfected.

$p<0.05$ for comparison of HIV-infected aviremic vs. HIV uninfected.

CMV, cytomegalovirus; CVL, cervicovaginal lavage, eGFR, estimated glomerular filtration rate, HCV, hepatitis C virus; ART, antiretroviral therapy; IL-6, interleukin 6; IP10, interferon gamma-induced protein. 
by the HIV-1 aviremic group (1.16) and the viremic group (0.36). The differences were all significant $(p<0.001)$.

Nearly all HIV-1 aviremic women reported currently using cART, compared to just over half of the HIV-1 viremic women. Therefore, HIV-1 aviremic women were significantly more likely to be on cART than viremic women $(p<0.001)$ (Table 1). We noted that there were three women in the aviremic group who were not on cART. These apparent elite controllers were included in the analyses shown in Tables 2 and 3, but we later ran the analysis excluding them and the results were similar.

The HIV-1 viremic group had a median plasma HIV-1 RNA copy number of 25,906/ml. Among women on cART at the time of the study, there was no difference in duration of therapy by group; the median time since cART initiation was 12.4 years (range 3.0-17.1 years) among HIV-1 viremic women and 11.3 years (range 1.9-17.2 years) among HIV-1 aviremic women $(p=0.487)$.

Raltegravir has been reported to have antiviral activity against CMV. ${ }^{42}$ Compared to HIV-1 viremic women, more women in the HIV-1 aviremic group were currently using raltegravir, although the difference was not statistically significant. There was no correlation between CMV IgG and raltegravir use among HIV-1-positive women currently on cART (data not shown).

Table 2. Association of Cytomegalovirus Immunoglobulin G with Sociodemographic and Clinical Variables by HIV-1 Status

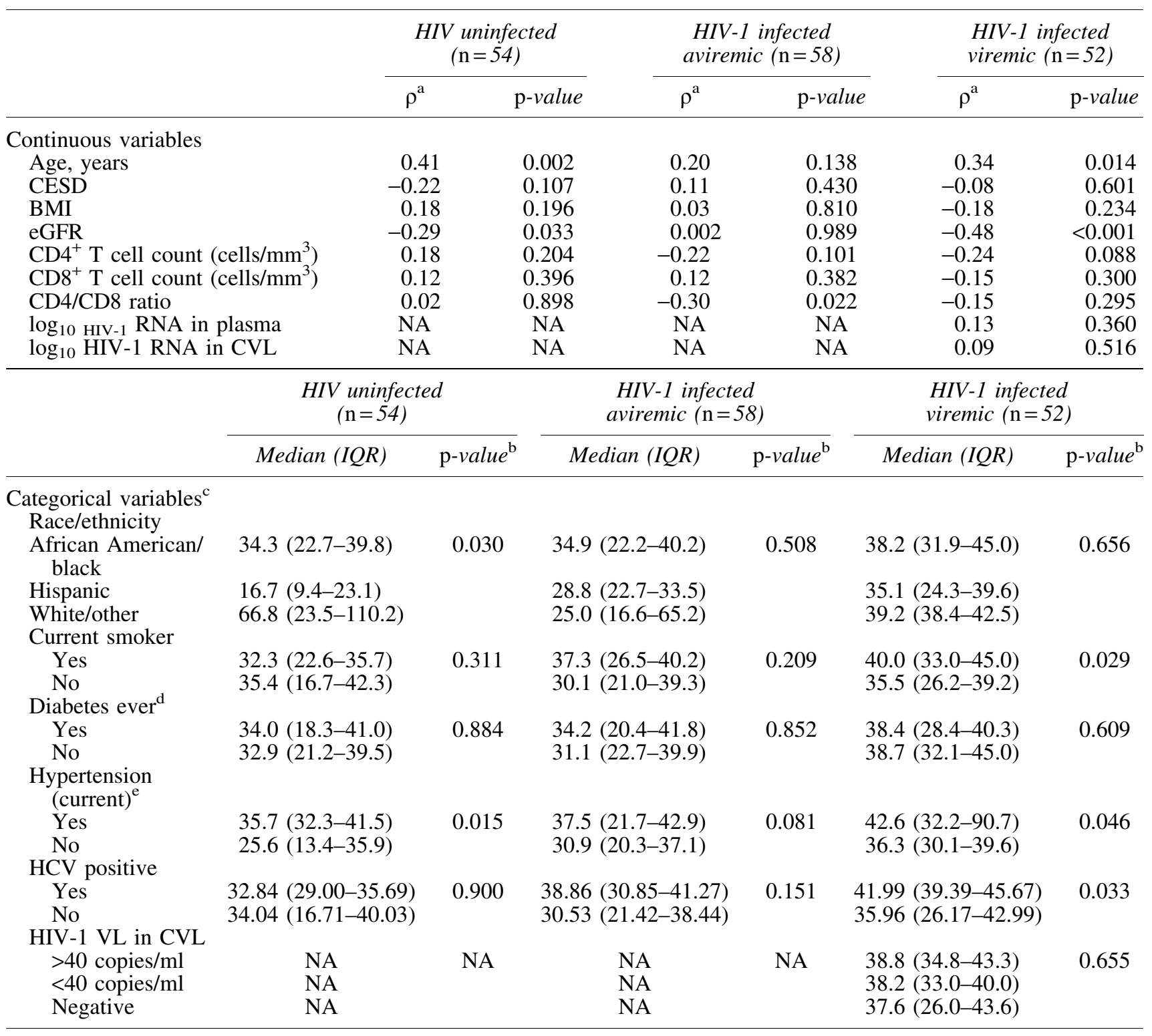

${ }^{\text {a }}$ Spearman rank correlation coefficient.

${ }^{\mathrm{b}} p$-values by Wilcoxan rank-sum test.

${ }^{c}$ Current employment, annual income, and education were not significant in any of the subgroups and are not shown in the table.

${ }^{\mathrm{d}}$ Every self-reported antidiabetic medication or any fasting glucose $\geq 126$ or hemoglobin $\mathrm{A}_{1 \mathrm{c}} \geq 6.5 \%$ or self-reported diabetes is confirmed.

${ }^{\mathrm{e}}$ Any indication of hypertension ( $\mathrm{SBP} \geq 140, \mathrm{DBP} \geq 90$, self-report, or use of antihypertensive medications) at visit. 
Table 3. Unadjusted and Adjusted Associations Between Cytomegalovirus and Inflammatory Markers by HIV-1 Status

\begin{tabular}{|c|c|c|c|c|c|c|c|c|c|c|}
\hline & \multicolumn{10}{|c|}{ HIV uninfected, $\mathrm{N}=54$} \\
\hline & \multicolumn{2}{|c|}{ IL-6 plasma } & \multicolumn{2}{|c|}{$I L-6 C V L$} & \multicolumn{2}{|c|}{$s C D 1$} & \multicolumn{2}{|c|}{$s C D 163$} & \multicolumn{2}{|c|}{ IP10 } \\
\hline & $\rho^{\mathrm{a}}$ & $\mathrm{p}$-value & $\rho^{\mathrm{a}}$ & $\mathrm{p}$-value & $\rho^{\mathrm{a}}$ & $\mathrm{p}$-value & $\rho^{\mathrm{a}}$ & $\mathrm{p}$-value & $\rho^{\mathrm{a}}$ & $\mathrm{p}$-value \\
\hline Unadjusted association & 0.24 & 0.081 & -0.13 & 0.344 & 0.10 & 0.471 & 0.10 & 0.470 & 0.21 & 0.133 \\
\hline $\begin{array}{l}\text { False discovery rate } \\
\text { adjusted } p \text {-value }\end{array}$ & & 0.238 & & 0.430 & & 0.471 & & 0.471 & & 0.249 \\
\hline \multicolumn{11}{|l|}{ Adjustment variables } \\
\hline Äge & 0.20 & 0.148 & 0.05 & 0.717 & -0.02 & 0.861 & -0.005 & 0.974 & 0.002 & 0.990 \\
\hline CD4 & 0.17 & 0.247 & -0.19 & 0.191 & 0.12 & 0.409 & 0.08 & 0.572 & 0.21 & 0.145 \\
\hline $\mathrm{HCV}$ & 0.24 & 0.092 & -0.17 & 0.235 & 0.12 & 0.390 & 0.08 & 0.594 & 0.19 & 0.168 \\
\hline BMI & 0.18 & 0.190 & -0.17 & 0.223 & 0.11 & 0.423 & 0.04 & 0.774 & 0.19 & 0.175 \\
\hline eGFR & 0.17 & 0.224 & -0.04 & 0.778 & 0.03 & 0.807 & 0.08 & 0.586 & 0.20 & 0.162 \\
\hline Smoking & 0.21 & 0.136 & -0.18 & 0.202 & 0.11 & 0.442 & 0.09 & 0.534 & 0.20 & 0.141 \\
\hline Hypertension & 0.15 & 0.286 & -0.12 & 0.378 & 0.04 & 0.801 & 0.003 & 0.985 & 0.12 & 0.405 \\
\hline \multirow[t]{4}{*}{ Black race } & 0.20 & 0.159 & -0.10 & 0.498 & 0.07 & 0.634 & 0.07 & 0.613 & 0.21 & 0.139 \\
\hline & \multicolumn{10}{|c|}{$H I V$ aviremic, $\mathrm{N}=58$} \\
\hline & \multicolumn{2}{|c|}{ IL-6 Plasma } & \multicolumn{2}{|c|}{$I L-6 C V L$} & \multicolumn{2}{|c|}{$s C D 14$} & \multicolumn{2}{|c|}{ sCD163 } & \multicolumn{2}{|c|}{ IP10 } \\
\hline & $\rho^{\mathrm{a}}$ & $\mathrm{p}$-value & $\rho^{\mathrm{a}}$ & $\mathrm{p}$-value & $\rho^{\mathrm{a}}$ & $\mathrm{p}$-value & $\rho^{\mathrm{a}}$ & $\mathrm{p}$-value & $\rho^{\mathrm{a}}$ & $\mathrm{p}$-value \\
\hline Unadjusted association & 0.21 & 0.114 & -0.10 & 0.450 & 0.27 & 0.039 & 0.17 & 0.193 & 0.15 & 0.261 \\
\hline $\begin{array}{l}\text { False discovery rate } \\
\text { adjusted } p \text {-value }\end{array}$ & & 0.244 & & 0.471 & & 0.146 & & 0.290 & & 0.356 \\
\hline \multicolumn{11}{|l|}{ Adjustment variables } \\
\hline Age & 0.20 & 0.133 & -0.05 & 0.702 & 0.23 & 0.082 & 0.12 & 0.370 & 0.11 & 0.424 \\
\hline CD4 & 0.24 & 0.069 & -0.09 & 0.504 & 0.29 & 0.026 & 0.15 & 0.281 & 0.13 & 0.323 \\
\hline $\mathrm{HCV}$ & 0.17 & 0.213 & -0.10 & 0.479 & 0.27 & 0.041 & 0.15 & 0.251 & 0.09 & 0.524 \\
\hline BMI & 0.21 & 0.119 & -0.12 & 0.378 & 0.30 & 0.025 & 0.17 & 0.203 & 0.15 & 0.257 \\
\hline eGFR & 0.21 & 0.116 & -0.11 & 0.436 & 0.28 & 0.038 & 0.18 & 0.190 & 0.15 & 0.259 \\
\hline Smoking & 0.21 & 0.126 & -0.09 & 0.488 & 0.26 & 0.049 & 0.20 & 0.127 & 0.16 & 0.231 \\
\hline Hypertension & 0.15 & 0.274 & -0.13 & 0.332 & 0.26 & 0.047 & 0.14 & 0.304 & 0.12 & 0.356 \\
\hline Black race & 0.21 & 0.116 & -0.09 & 0.499 & 0.30 & 0.022 & 0.19 & 0.168 & 0.18 & 0.187 \\
\hline
\end{tabular}

HIV viremic, $\mathrm{N}=52$

\begin{tabular}{|c|c|c|c|c|c|c|c|c|c|c|}
\hline & \multirow{2}{*}{\multicolumn{2}{|c|}{ IL-6 plasma }} & \multirow{2}{*}{\multicolumn{2}{|c|}{$I L-6 C V L$}} & \multirow{2}{*}{\multicolumn{2}{|c|}{ sCD14 }} & \multirow{2}{*}{\multicolumn{2}{|c|}{$s C D 163$}} & \multirow{2}{*}{\multicolumn{2}{|c|}{ IP10 }} \\
\hline & & & & & & & & & & \\
\hline & $\rho^{\mathrm{a}}$ & $\mathrm{p}$-value & $\rho^{\mathrm{a}}$ & $\mathrm{p}$-value & $\rho^{\mathrm{a}}$ & p-value & $\rho^{\mathrm{a}}$ & $\mathrm{p}$-value & $\rho^{\mathrm{a}}$ & $\mathrm{p}$-value \\
\hline Unadjusted association & 0.31 & 0.023 & -0.32 & 0.021 & 0.43 & 0.002 & 0.23 & 0.095 & 0.20 & 0.150 \\
\hline $\begin{array}{l}\text { False discovery rate } \\
\text { adjusted } p \text {-value }\end{array}$ & & 0.115 & & 0.115 & & 0.030 & & 0.238 & & 0.250 \\
\hline \multicolumn{11}{|l|}{ Adjustment variables } \\
\hline Äge & 0.26 & 0.064 & -0.26 & 0.069 & 0.33 & 0.018 & 0.16 & 0.252 & 0.15 & 0.286 \\
\hline CD4 & 0.30 & 0.036 & -0.30 & 0.036 & 0.40 & 0.005 & 0.23 & 0.114 & 0.16 & 0.277 \\
\hline Viral load & 0.29 & 0.036 & -0.33 & 0.021 & 0.42 & 0.002 & 0.20 & 0.160 & 0.16 & 0.264 \\
\hline cART since last visit & 0.28 & 0.047 & -0.23 & 0.105 & 0.35 & 0.011 & 0.29 & 0.040 & 0.20 & 0.150 \\
\hline $\mathrm{HCV}$ & 0.28 & 0.045 & -0.25 & 0.082 & 0.39 & 0.005 & 0.16 & 0.272 & 0.12 & 0.424 \\
\hline BMI & 0.31 & 0.033 & -0.33 & 0.024 & 0.39 & 0.007 & 0.23 & 0.127 & 0.19 & 0.193 \\
\hline eGFR & 0.20 & 0.151 & -0.26 & 0.064 & 0.24 & 0.087 & 0.08 & 0.590 & 0.16 & 0.262 \\
\hline Smoking & 0.24 & 0.091 & -0.30 & 0.034 & 0.36 & 0.011 & 0.25 & 0.084 & 0.17 & 0.234 \\
\hline Hyperte & 0.24 & 0.083 & -0.3 & 0.012 & 0.39 & 0.005 & 0.23 & 0.111 & 0.18 & 0.216 \\
\hline Black race & 0.31 & 0.025 & -0.33 & 0.021 & 0.43 & 0.002 & 0.24 & 0.092 & 0.20 & 0.152 \\
\hline
\end{tabular}

${ }^{\text {a S}}$ Spearman rank correlation coefficient.

HCV has been reported to have an impact on T cell phenotypes in HIV-1-infected persons. ${ }^{43}$ Although there was no significant difference in $\mathrm{HCV}$ serostatus between the groups, there was a significant association of HCV seropositivity with CMV IgG levels among HIV-1 viremic women.
HIV-1 RNA was analyzed in CVL supernatant fluids. HIV1 viremic women were much more likely to have detectable HIV-1 RNA in CVL than HIV-1 aviremic women. Only one woman with undetectable HIV-1 RNA in plasma had detectable HIV-1 RNA in CVL (Table 1). 
Biomarkers of inflammation and immune activation associated with HIV-1 status

Plasma biomarkers IL-6, sCD14, sCD163, and IP10 and CVL IL-6 were measured and compared among the three groups of women. Levels of these markers measured in the HIV-1 viremic group were significantly higher than those in either the HIV-1 aviremic or the uninfected groups (Table 1). The sCD14, sCD163, and IP10 values followed a significant trend with the highest median value found in the HIV-1 viremic group followed by the aviremic group, and the lowest median value in the uninfected group (all $p$ values $<0.001$ ) (Table 1). Plasma IL-6 levels in the HIV-1 viremic group were higher than in the other groups, however HIV-1 aviremic women had lower levels than uninfected women. A similar pattern was found for CVL IL-6.

\section{Association of CMV IgG with sociodemographic and clinical characteristics}

After establishing differences among the three groups related to sociodemographic and clinical characteristics, we examined associations with CMV IgG levels (Table 2). Significant negative associations between CMV IgG levels and eGFR were found for HIV-1-uninfected and HIV-1 viremic women. The $\mathrm{CD}^{+} / \mathrm{CD}^{+}$cell ratio was significantly associated with CMV IgG levels in aviremic women $(p=0.022)$.

Age was significantly associated with CMV IgG for the HIV-1 viremic women and HIV-1-uninfected women. African American race among HIV-1-uninfected women $(p=0.03)$, current smoking among HIV-1 viremic women $(p=0.029)$, and hypertension among both HIV-1-uninfected $(p=0.046)$ and HIV-1 viremic ( $p=0.015)$ women were significantly associated with CMV IgG levels (Table 2).

\section{Biomarkers of inflammation and immune activation associated with CMV IgG}

We investigated the association of CMV IgG with the selected biomarkers of activation and inflammation and also with HIV-1 status/viremia. For HIV-1-uninfected women, there were no significant unadjusted associations between CMV IgG levels and plasma levels of IL-6, sCD14, sCD163, and IP10 or CVL levels of IL-6 (Table 3).

Among HIV-1 aviremic women, the unadjusted correlation of sCD14 with CMV IgG levels was 0.27 (raw $p=0.039$; FDR adjusted $p=0.15$ ); the magnitude of the correlation was similar when single variable adjustments were made for CD4 count, HCV antibody positivity, BMI, smoking, hypertension, eGFR, and black race ( $p$-values $<0.05$ ). Among HIV-1 viremic women, there was a significant unadjusted positive association of plasma IL-6 $(p=0.023)$ and negative association of CVL IL-6 $(p=0.021)$ with CMV IgG. The FDR adjusted was $p=0.115$ for both. The magnitude of the correlations for plasma IL-6 was similar when single adjustments were made for CD4, viral load, cART, HCV, and BMI. For CVL IL-6 the correlations remained significant with single adjustments for CD4, viral load, BMI, and smoking.

Among HIV-1 viremic women, sCD14 had the strongest (Spearman $r=0.3-0.4)$ and most consistently significant positive association with CMV $\operatorname{IgG}(r=0.43$; raw $p=0.002$; FDR adjusted $p=0.030$ ), which remained significant with adjustment for age, CD4 count, HIV-1 viral load, cART use,
HCV infection, smoking, hypertension, BMI, and black race ( $p \leq 0.018$ for all; Table 3). Significance or a trend toward significance for sCD14 also remained with adjustments for multiple variables: age plus CD4 ( $p=0.051)$, age plus HIV-1 viral load ( $p=0.025)$, or age plus HCV $(p=0.022)$ (data not shown). However, after adjustment for eGFR the association of CMV IgG with sCD14 was attenuated ( $r=0.24 ; p=0.087)$.

\section{Discussion}

In this study of HIV and CMV coinfection, we found significant differences in levels of markers of inflammation and immune activation among three groups of women enrolled in the WIHS: HIV uninfected, HIV infected aviremic, and HIV infected viremic. Viremic women had the highest levels of all markers among the three groups. The unadjusted association of these markers with CMV IgG among aviremic women was statistically significant as was adjustment for single variables CD4 counts, HCV, BMI, eGFR, smoking, hypertension, and race. Unadjusted and adjusted associations for these same single variables among viremic women were all significant with $p$ values $\leq 0.025$, except for eGFR. In contrast, there were no significant associations between CMV IgG and any of the biomarkers among HIV-1-uninfected CMV-seropositive women.

We noted that among viremic women the correlation of sCD14 and CMV IgG was attenuated with the adjustment for eGFR. A significant negative association between CMV IgG levels and eGFR was reported in a study of elderly HIV-1uninfected adults. ${ }^{44}$ A significant negative association between sCD14 and eGFR was reported in a study of patients with chronic kidney disease. ${ }^{45}$ These associations as well as our data call for future investigation to determine the relationship among CMV IgG, sCD14, and eGFR.

Our results differ from others in that the group that showed the strongest association between sCD14 and CMV IgG levels was HIV-1 viremic. ${ }^{15,16,21}$ However, a limitation of our study is the lack of a $\mathrm{CMV}^{-} / \mathrm{HIV}-1^{+}$group of women, which is difficult to acquire with the high seroprevalence of CMV among HIV-1-infected persons. A second limitation is the cross-sectional design of the study. Classifications of HIV viremic and aviremic might change at different time points as a result of the degree of adherence to therapy or the effectiveness of drug regimens. In addition, the level of HIV viral load among the viremic women ranged from approximately 5,000 to 63,000 HIV RNA copies per $\mathrm{ml}$, which may have led to residual confounding of the association between CMV IgG and inflammatory markers by HIV viremia, although the association of sCD14 and CMG IgG levels among viremic women remained significant after controlling for HIV RNA.

Finally, we cannot rule out the role of other viral copathogens in increased levels of IgG and biomarkers of inflammation and immune activation. There have been reports that HIV infection affects B cell function leading to nonspecific hypergammaglobulinemia. ${ }^{18,46}$ Brunt et al. ${ }^{18}$ reported elevated levels of CMV and Epstein-Barr virus (EBV) antibodies over a period of 10 years after initiation of cART in a small group of nine CMV-seropositive patients. SCD14 levels were not associated with CMV antibody over this time period. Burdo et al. ${ }^{22}$ found a positive correlation of SCD163 in HIV-1-infected patients with CMV IgG and SCD14 but no correlation with EBV IgG. Although we did not test for IgG 
specific for other herpesviruses, we have participated in a study of CMV pathogenesis in another WIHS cohort, ${ }^{9}$ in which quantitation of EBV-specific antibody showed no association of EBV IgG with CMV IgG-associated pathogenesis. The exploratory nature of the present study limited our ability to investigate the interaction of other viruses with HIV in HIV-infected patients; however, our data have led us to focus on the association between CMV and SCD14.

SCD14 is a receptor for lipopolysaccharide ${ }^{47}$ and a marker of microbial translocation and monocyte activation, which has been reported to be an independent predictor of non-AIDSdefining disease in HIV-1-infected patients. ${ }^{15,17,33}$ Among these studies, SCD14 was reported to be associated with coronary calcification, an indicator of atherosclerosis in HIV1 -infected patients on cART. ${ }^{15}$ It was also reported that in HIV-1-infected patients, sCD14 together with gut epithelial barrier dysfunction was predictive of increased mortality. ${ }^{33}$

The monocyte appears to play a central role in HIV-1 pathogenesis. Monocyte activation may persist even with successful cART, and monocytes may be the vector for transmission of viruses to the central nervous system. ${ }^{4,11,23}$ Nonclassical monocyte phenotypes $\left(\mathrm{CD} 14^{++} / \mathrm{CD} 16^{+}\right.$or $\mathrm{CD} 14^{+} / \mathrm{CD} 16^{++}$) were found to be activated by exposure to HIV-1 and have also been reported to be infected by HIV- $1 .{ }^{4}$

At the same time, monocytes are known to be sites of CMV latency, ${ }^{48}$ although they are not permissive for virus replication. In the absence of HIV-1, induction of replicating CMV has been shown to occur with the terminal differentiation of monocytes to myeloid dendritic cells, ${ }^{49}$ and in vitro studies have demonstrated that monocyte to macrophage differentiation leads to production of infectious virus. ${ }^{50-52}$ If HIV-1 infection activates monocytes and macrophages, ${ }^{53}$ it is likely that CMV could be reactivated and replicate leading to an inflammatory response. In our study the association of CMV IgG with sCD14 within the HIV-1 viremic group, which was not present in the HIV-uninfected group, suggests that coinfection and long-term interaction of HIV-1 and CMV may lead to the development of serious non-AIDS events.

Non-AIDS-defining morbidity and mortality have also been associated with increased $\mathrm{CD} 8^{+} \mathrm{T}$ cells and a decreased ratio of $\mathrm{CD}^{+} / \mathrm{CD}^{+}$, which remains low in patients who have been successfully treated with cART. ${ }^{10,34}$ Our data support these findings, suggesting that the ratio did not return to normal despite control of the HIV-1 viral load. Of note is the significant negative association of the $\mathrm{CD} 4^{+} / \mathrm{CD} 8^{+}$ratio with CMV IgG among the group of aviremic women (Table 2). This could be the result of enhancement of $\mathrm{CD}^{+} \mathrm{T}$ cell responses to $\mathrm{CMV}{ }^{25,54}$

A low $\mathrm{CD}^{+} / \mathrm{CD}^{+}$ratio has also been shown to correlate inversely with $\mathrm{sCD} 14,{ }^{10}$ which provides a potential link between innate immune activation and elevated $\mathrm{CD}^{+} \mathrm{T}$ cell counts through inflammation. Finally, CMV infection alone has been associated with driving an inverted $\mathrm{CD} 4^{+} / \mathrm{CD} 8^{+}$ratio in older persons. ${ }^{55,56}$ The eventual outcome of these clinical correlates may be an increase in non-AIDS-associated morbidity and mortality. ${ }^{17}$

From the results of this study, we propose a model of HIV1 and CMV coinfection, based on the significant association of CMV IgG with sCD14 levels in women who are HIV-1 viremic and CMV seropositive. CMV primary infection results in asymptomatic latency in multiple cell types including monocytes. ${ }^{48}$ HIV-1 infection activates monocytes, which may lead to reactivation of CMV from latency in these cells. In addition, differentiation of monocytes to macrophages produces a cell that is permissive for CMV replication. ${ }^{50}$ Reactivation of CMV may result in production of biomarkers of inflammation and immune activation such as sCD14, IL-6, sCD163, and IP10. ${ }^{22,47,51,57}$ An increase in CMV IgG and CMV-specific T cells may result in temporary control of infection, but the potential for additional cycles of reactivation and inflammation would be predicted to result in cellular and tissue damage. The extent of the damage would depend on the body compartment(s) involved and the magnitude and frequency of the immunological response to the infections. The results that we report suggest that future studies should include in vitro analysis of HIV/CMV coinfection in monocytes with activation to macrophages, as well as analysis of coinfection in monocytes from HIV/CMV-seropositive patients.

\section{Acknowledgments}

Data in this article were collected by the Chicago site of the Women's Interagency HIV-1 Study (WIHS). The contents of this publication are solely the responsibility of the authors and do not represent the official views of the National Institutes of Health (NIH). Chicago WIHS (Mardge Cohen), U01-AI-034993; The WIHS is funded primarily by the National Institute of Allergy and Infectious Diseases (NIAID), with additional co-funding from the Eunice Kennedy Shriver National Institute of Child Health and Human Development (NICHD), the National Cancer Institute (NCI), the National Institute on Drug Abuse (NIDA), and the National Institute on Mental Health (NIMH).

This work was also supported in part by the National Institutes of Health funded Chicago Developmental Center for AIDS Research P30 AI082151 (to A.L.) The authors wish to thank Ralph Morak, Dominika Drupka, and Salvatore Scianna for their technical assistance.

\section{Author Disclosure Statement}

No competing financial interests exist for any of the authors.

\section{References}

1. Ford N, Shubber Z, Saranchuk P, et al.: Burden of HIVrelated cytomegalovirus retinitis in resource-limited settings: A systematic review. Clin Infect Dis 2013;57(9): 1351-1361.

2. Tun N, Smithuis FM, London N, et al.: Mortality in patients with AIDS-related cytomegalovirus retinitis in Myanmar. Clin Infect Dis 2014;59:1650-1651.

3. Deayton JR, Prof Sabin CA, Johnson MA, et al.: Importance of cytomegalovirus viraemia in risk of disease progression and death in HIV-infected patients receiving highly active antiretroviral therapy. Lancet 2004;363(9427):2116-2121.

4. Campbell JH, Hearps AC, Martin GE, et al.: The importance of monocytes and macrophages in HIV pathogenesis, treatment, and cure. AIDS 2014;28(15):2175-2187.

5. Lederman MM, Funderburg NT, Sekaly RP, et al.: Residual immune dysregulation syndrome in treated HIV infection. Adv Immunol 2013;119:51-83.

6. Barrett L, Fowke KR, and Grant MD: Cytomegalovirus, aging, and HIV: A perfect storm. AIDS Rev 2012;14(3):159167. 
7. Lichtner M, Cicconi P, Vita S, et al.: Cytomegalovirus coinfection is associated with an increased risk of severe non-AIDS-defining events in a large cohort of HIV-infected patients. J Infect Dis 2015;211:178-186.

8. Naeger DM, Martin JN, Sinclair E, et al.: Cytomegalovirusspecific $\mathrm{T}$ cells persist at very high levels during long-term antiretroviral treatment of HIV disease. PloS One 2010;5(1): e8886.

9. Parrinello CM, Sinclair E, Landay AL, et al.: Cytomegalovirus immunoglobulin $G$ antibody is associated with subclinical carotid artery disease among HIV-infected women. J Infect Dis 2012;205(12):1788-1796.

10. Serrano-Villar S, Sainz T, Lee SA, et al.: HIV-infected individuals with low CD4/CD8 ratio despite effective antiretroviral therapy exhibit altered $\mathrm{T}$ cell subsets, heightened CD8+ $\mathrm{T}$ cell activation, and increased risk of non-AIDS morbidity and mortality. PLoS Pathog 2014;10(5):e1004078.

11. Tenorio AR, Zheng Y, Bosch RJ, et al.: Soluble markers of inflammation and coagulation but not $\mathrm{T}$-cell activation predict non-AIDS-defining morbid events during suppressive antiretroviral treatment. J Infect Dis 2014;210(8):1248-1259.

12. Duprez DA, Neuhaus J, Kuller LH, et al.: Inflammation, coagulation and cardiovascular disease in HIV-infected individuals. PloS One 2012;7(9):e44454.

13. Kaplan RC, Sinclair E, Landay AL, et al.: T cell activation and senescence predict subclinical carotid artery disease in HIV-infected women. J Infect Dis 2011;203(4):452-463.

14. Kuller LH, Tracy R, Belloso W, et al.: Inflammatory and coagulation biomarkers and mortality in patients with HIV infection. PLoS Med 2008;5(10):e203.

15. Longenecker CT, Jiang Y, Orringer CE, et al.: Soluble CD14 is independently associated with coronary calcification and extent of subclinical vascular disease in treated HIV infection. AIDS 2014;28(7):969-977.

16. Merlini E, Luzi K, Suardi E, et al.: T-cell phenotypes, apoptosis and inflammation in HIV+ patients on virologically effective cART with early atherosclerosis. PloS One 2012;7(9): e46073.

17. Sandler NG, Wand H, Roque A, et al.: Plasma levels of soluble CD14 independently predict mortality in HIV infection. J Infect Dis 2011;203(6):780-790.

18. Brunt SJ, Lee S, D'Orsogna L, et al.: The use of humoral responses as a marker of CMV burden in HIV patients on ART requires consideration of T-cell recovery and persistent B-cell activation. Dis Mark 2014;2014:947432.

19. Letendre S, Bharti A, Perez-Valero I, et al.: Higher CMV antibody concentrations are associated with older age, lower nadir CD4+ cell counts, and worse global neurocognitive functioning in people with HIV disease. Poster 466 19th Conference on Retroviruses and Opportunisitic Infections, Seattle, WA, March 5-8, 2012.

20. Noel N, Boufassa F, Lecuroux C, et al.: Elevated IP10 levels are associated with immune activation and low CD4(+) T-cell counts in HIV controller patients. AIDS 2014;28(4):467-476.

21. Masia M, Robledano C, Ortiz de la Tabla V, et al.: Increased carotid intima-media thickness associated with antibody responses to varicella-zoster virus and cytomegalovirus in HIVinfected patients. PloS One 2013;8(5):e64327.

22. Burdo TH, Lo J, Abbara S, et al.: Soluble CD163, a novel marker of activated macrophages, is elevated and associated with noncalcified coronary plaque in HIV-infected patients. J Infect Dis 2011;204(8):1227-1236.

23. Funderburg NT, Zidar DA, Shive C, et al.: Shared monocyte subset phenotypes in HIV-1 infection and in uninfected sub- jects with acute coronary syndrome. Blood 2012;120(23): 4599-4608.

24. Hsue PY, Hunt PW, Sinclair E, et al.: Increased carotid intima-media thickness in HIV patients is associated with increased cytomegalovirus-specific T-cell responses. AIDS 2006;20(18):2275-2283.

25. Hunt PW, Martin JN, Sinclair E, et al.: Valganciclovir reduces $\mathrm{T}$ cell activation in HIV-infected individuals with incomplete CD4+ T cell recovery on antiretroviral therapy. J Infect Dis 2011;203(10):1474-1483.

26. Gianella S, Anderson CM, Vargas MV, et al.: Cytomegalovirus DNA in semen and blood is associated with higher levels of proviral HIV DNA. J Infect Dis 2013;207(6):898-902.

27. Gianella S, Massanella M, Richman DD, et al.: Cytomegalovirus replication in semen is associated with higher levels of proviral HIV DNA and CD4+ T cell activation during antiretroviral treatment. J Virol 2014;88(14):7818-7827.

28. Gianella S, Morris SR, Anderson C, et al.: Herpes viruses and HIV-1 drug resistance mutations influence the virologic and immunologic milieu of the male genital tract. AIDS 2013;27(1):39-47.

29. Gianella S, Morris SR, Vargas MV, et al.: Role of seminal shedding of herpesviruses in HIV Type 1 transmission. $\mathbf{J}$ Infect Dis 2013;207(2):257-261.

30. Gianella S, Smith DM, Vargas MV, et al.: Shedding of HIV and human herpesviruses in the semen of effectively treated HIV-1-infected men who have sex with men. Clin Infect Dis 2013;57(3):441-447.

31. Lurain NS, Robert ES, Xu J, et al.: HIV type 1 and cytomegalovirus coinfection in the female genital tract. J Infect Dis 2004;190(3):619-623.

32. Schoenfisch AL, Dollard SC, Amin M, et al.: Cytomegalovirus (CMV) shedding is highly correlated with markers of immunosuppression in CMV-seropositive women. J Med Microbiol 2011;60(Pt 6):768-774.

33. Hunt PW, Sinclair E, Rodriguez B, et al.: Gut epithelial barrier dysfunction and innate immune activation predict mortality in treated HIV infection. J Infect Dis 2014;210(8):1228-1238.

34. Barrett L, Stapleton SN, Fudge NJ, et al.: Immune resilience in HIV-infected individuals seronegative for cytomegalovirus. AIDS 2014;28(14):2045-2049.

35. Barkan SE, Melnick SL, Preston-Martin S, et al.: The Women's Interagency HIV Study. WIHS Collaborative Study Group. Epidemiology 1998;9(2):117-125.

36. Hessol NA, Weber KM, Holman S, et al.: Retention and attendance of women enrolled in a large prospective study of HIV-1 in the United States. J Women's Health 2009;18(10): 1627-1637.

37. Radloff LS: A simple sequentially rejective multiple test procedure. Appl Psychol Measure 1977;1:65-70.

38. Levey AS, Bosch JP, Lewis JB, et al.: A more accurate method to estimate glomerular filtration rate from serum creatinine: A new prediction equation. Modification of Diet in Renal Disease Study Group. Ann Intern Med 1999;130(6): 461-470.

39. Holm S: A simple sequentially rejective multiple test procedure. Scand J Stat 1979;6:65-70.

40. Benjamini Y and Hochberg Y: Controlling the false discovery rate: A practical and powerful approach to multiple testing. J R Stat Soc Ser B 1995;57(1):289-300.

41. Goossens VJ, Wolffs PF, van Loo IH, et al.: CMV DNA levels and CMV gB subtypes in ART-naive HAARTtreated patients: A 2-year follow-up study in The Netherlands. AIDS 2009;23(11):1425-1429. 
42. Zhou B, Yang K, Wills E, et al.: A mutation in the DNA polymerase accessory factor of herpes simplex virus 1 restores viral DNA replication in the presence of raltegravir. J Virol 2014;88(19):11121-11129.

43. Kuniholm MH, Xie X, Anastos K, et al.: Association of chronic hepatitis $\mathrm{C}$ infection with $\mathrm{T}$-cell phenotypes in HIV-negative and HIV-positive women. J Acquir Immune Defic Syndr 2014;67(3):295-303.

44. Jeong SJ, Han SH, Kim CO, et al.: Association between human cytomegalovirus antibody levels, and essential hypertension and functional status in elderly Koreans. Geriatr Gerontol Int 2014. [Epub ahead of print]; DOI:10.1111/ggi.12428.

45. Poesen R, Ramezani A, Claes K, et al.: Associations of soluble CD14 and endotoxin with mortality, cardiovascular disease, and progression of kidney disease among patients with CKD. Clin J Am Soc Nephrol 2015;10:1525-1533.

46. Boliar S, Murphy MK, Tran TC, et al.: B-lymphocyte dysfunction in chronic HIV-1 infection does not prevent crossclade neutralization breadth. J Virol 2012;86(15):8031-8040.

47. Yew KH, Carpenter C, Duncan RS, et al.: Human cytomegalovirus induces TLR4 signaling components in monocytes altering TIRAP, TRAM and downstream interferon-beta and TNF-alpha expression. PloS One 2012;7(9):e44500.

48. Larsson S, Soderberg-Naucler C, Wang FZ, et al.: Cytomegalovirus DNA can be detected in peripheral blood mononuclear cells from all seropositive and most seronegative healthy blood donors over time. Transfusion 1998;38(3):271-278.

49. Reeves MB and Sinclair JH: Circulating dendritic cells isolated from healthy seropositive donors are sites of human cytomegalovirus reactivation in vivo. $\mathrm{J}$ Virol 2013;87(19):10660-10667.

50. Bayer C, Varani S, Wang L, et al.: Human cytomegalovirus infection of M1 and M2 macrophages triggers inflammation and autologous T-cell proliferation. J Virol 2013;87(1):67-79.

51. Smith PD, Shimamura M, Musgrove LC, et al.: Cytomegalovirus enhances macrophage TLR expression and MyD88- mediated signal transduction to potentiate inducible inflammatory responses. J Immunol 2014;193(11):5604-5612.

52. Van Damme E, Sauviller S, Lau B, et al.: Glucocorticosteroids trigger reactivation of human cytomegalovirus from latently infected myeloid cells and increase the risk for HCMV infection in D+R+ liver transplant patients. J Gen Virol 2015;96(Pt 1):131-143.

53. Longenecker CT, Funderburg NT, Jiang Y, et al.: Markers of inflammation and CD8 T-cell activation, but not monocyte activation, are associated with subclinical carotid artery disease in HIV-infected individuals. HIV Med 2013;14(6):385-390.

54. Shin LY, Sheth PM, Persad D, et al.: Impact of CMV therapy with valganciclovir on immune activation and the HIV viral load in semen and blood: An observational clinical study. J Acquir Immune Defic Syndr 2014;65(3):251-258.

55. Wikby A, Mansson IA, Johansson B, et al.: The immune risk profile is associated with age and gender: Findings from three Swedish population studies of individuals 20 100 years of age. Biogerontology 2008;9(5):299-308.

56. Strindhall J, Skog M, Ernerudh J, et al.: The inverted CD4/ CD8 ratio and associated parameters in 66-year-old individuals: The Swedish HEXA immune study. Age 2013;35(3): 985-991.

57. Weseslindtner L, Nachbagauer R, Kundi M, et al.: Human cytomegalovirus infection in lung transplant recipients triggers a CXCL-10 response. Am J Transplant 2011;11(3): 542-552.

Address correspondence to: Nell S. Lurain

Department of Immunology/Microbiology Rush University Medical Center 1735 West Harrison Street, Room 606 Cohn Chicago, Illinois 60612

E-mail: nlurain@rush.edu 